\title{
The Effect of the MRET Wave Rider Device on Cerebral Blood Flow and the Blood Brain Barrier: A Case Study
}

\author{
Smirnov IV $^{1, *}$, Fisher $\mathrm{HW}^{2}$ \\ ${ }^{1}$ CEO Global Quantech, Riga, Latvia \\ ${ }^{2}$ Senior Academic Dean, HOC Academy, Radcliff, Kentucky \\ ${ }^{\star}$ Corresponding author: Smirnov IV, CEO Global Quantech, Riga, Latvia, E-mail: info@gqusa.com
}

Received Date: April 09, 2018; Accepted Date: May 18, 2018; Published Date: May 21, 2018

Citation: Smirnov IV (2018) The Effect of the Mret Wave Rider Device on Cerebral Blood Flow and the Blood Brain Barrier: A Case Study. J Nanotech Smart Mater 3: 1-8.

\begin{abstract}
Biological effects of electromagnetic fields (EMF) on the blood-brain barrier (BBB) and cerebral blood flow can be studied using optical encephalography. Previous investigations of the permeability of the blood-brain barrier after exposure to the various EMF-components showed an induced leakage of Evans Blue labeled proteins normally not passing the BBB. In the present investigation we exposed a human subject to ambient radiation and the flow of the blood at the frontal part of the brain was measured using16-channel optical encephalography. The Optical Encephalograph is a functional Near-Infrared Spectroscopy (fNIRS) device that monitors PO2 and Hemoglobin ( $\mathrm{Hb}$ ) levels and translates the data into an indication of blood flow. The MRET WaveRider noise field generator which is capable of decreasing BBB permeability by neutralizing EMR was turned onand the flow of the blood at the frontal part of the brain was measured using 16-channel optical encephalography. The MRET polymer compound is driven by the solenoid that encapsulates the polymer material (WaveRider ${ }^{\circledast}$ ). The composite noise field can modify RF signals as a result of superposition phenomenon. When the WaveRider noise field was in effect, the cerebral blood flow (increased PO2 and $\mathrm{Hb}$ ) increased from 337.209 seconds to 864.419 seconds at the termination of the testing, indicating that these measurements were previous to the Wave Rider initiation affects.
\end{abstract}

\section{Introduction}

The current literature indicates that the environment poses potential risks for the global population on a daily basis from ambient electromagnetic fields (EMFs) otherwise known as electromagnetic radiation. EMR is unavoidable and certainly there are established relationships between multiple cancers such as leukemia and gliomas, hormonal dysfunction, miscarriage, fertility issues and numerous other negative effects on the central nervous system, the immune system and many or all of the more than one hundred trillion cells in the body [1-14]. While affecting every cell in the body, EMR predominantly affects neurological tissue and the largest collection of neurological tissue is the brain and spinal cord. It has been well documented that all mobile communication equipment such as cell phones, which emit electromagnetic fields in the radio frequency range, and other microwave emitting and receiving devices such as cordless phones, can cause DNA damage such as DNA breaks, headaches, blurred vision, dizziness, fatigue, short term memory loss, neuralgias, tumors, sleep disturbances, aberrant brain wave activity and changes to cerebral blood flow, including altering the permeability of the blood brain, association and dose-relationships between microwave emitting electronics such as cell phone usage and disease, place cell phone users into an identified high-risk health group $[15,16]$. EMR effects are absorbed and as opposed to a single dose response, affect tissue on a cumulative basis. Recent studies have concluded that cell phone users for greater than ten years have a significantly increased risk of glioma, a form of brain tumor [17]. Salford's work demonstrating the involvement of altered permeability in the BBB, potentially indicate that dementia related diseases including Alzheimer's Disease (AD) and other inflammatory diseases may be negatively affected. Engineer Lloyd Morgan has hypothesized, that based on the similarities between the incubation period for tumor growth in conjunction with the demonstrable dose-response relationship found with cell phone usage and brain cancer $[18,19]$, that one can expect more than $400,000,000$ cases of brain tumor by the middle of the next decade [20]. This finding bears a striking resemblance to the epidemiological studies linking cigarettes to lung cancer [21]. 
The Blood-Brain Barrier (BBB) is an organic barrier between circulating blood and the central nervous system responsible for regulating the exchange of substances between blood and the brain [22]. At the same time it acts as a protective shield by preventing the penetration of harmful substances and pathogens into the brain fluid. The BBB thus plays a key role in the generation and maintenance of chronic inflammation during $\mathrm{AD}$ and therefore expands the ramifications of the effects of preventing BBB permeability. The BBB functions as part of the neurovascular unit (NVU). This unit includes clusters of the neurological tissues: glial cells, neurons and pericytes [23]. Exposure to levels of radiofrequency electromagnetic fields (EMF) that increase brain temperature by more than $1^{\circ} \mathrm{C}$ can reversibly increase the permeability of the $\mathrm{BBB}$ for macromolecules and expose the brain to macromolecule passing through [24].

A double-blind study on the effects of a mobile phone on regional cerebral blood flow ( $\mathrm{rCBF}$ ) in healthy humans using positron emission tomography (PET) imaging documented the fact that mobile phone usage affects blood flow in humans [25]. "The mammalian blood-brain barrier (BBB) consists of endothelial cells, linked by tight junctions, and the adjoining pericytes and extracellular matrix. It helps maintain a highly stable extracellular environment necessary for accurate synaptic transmission and protects nervous tissue from injury. An increase in its normally low permeability for hydrophilic and charged molecules could potentially be detrimental [26]." EMR causes increased BBB permeability [27-34]. BBB increased permeability decreases cerebral blood flow and conversely one may confer that increased cerebrovascular blood flow indicates a decrease to BBB permeability $[35,36]$.

Noise fields have been found to intervene or eliminate electromagnetic radiation (EMR) effects [37-42]. A piezoelectric liquid crystal polymer of fractal geometry, Molecular Resonance Effect Technology (MRET), capable of generating a magnetic noise field, is used in the construction of a noise field generator (WaveRider ${ }^{\circledast}$ ) that has been shown to significantly decrease the physiological effects of electromagnetic radiation by interrupting the physiological perception of the waveform [43-49].

In the case of the MRET epoxy polymer, the kinetics to a large extent determine the final crystalline structure of the polymer. The introduction of foreign agents (substances) in the parent lattice of epoxy polymer leads to the effect of superimposed periodicity and, as a result, develops modulated crystalline structures with specific fractal microstructure, phase transition, network topology and polarity. Due to the fractal structures of MRET polymer compound and the phenomenon of piezoelectricity this polymer generates a subtle, low frequency, non-coherent electromagnetic field (composite noise field) when exposed to an electromagnetic field of 7.8 $\mathrm{Hz}$ and $14.5 \mathrm{~Hz}$ frequency oscillating in a repeating sequence for 5 seconds each time. In the WaveRider ${ }^{\oplus}$, the MRET polymer compound is driven by the solenoid that encapsulates the polymer material creating a magnetic noise field which has been confirmed by laboratory testing by Nemko USA Inc. of Carlsbad, California.
Superposition phenomenon is a physical process that can modify RF waves. MRET generator (Wave Rider) produces a composite noise field that is superimposed on RF microwave oscillations. It leads to amplitude modulation of RF carrier waves. In this case the random electromagnetic signals generated by MRET Wave Rider device is a modulating signal and carrier RF signal is a modulated one [50].

In the present investigation we exposed a human subject to ambient radiation and the flow of the blood at the frontal part of the brain was measured using 16-channel optical encephalography. The Optical Encephalograph is a functional Near-Infrared Spectroscopy (fNIRS) device that monitors PO2 and Hemoglobin $(\mathrm{Hb})$ levels and translates the data into an indication of blood flow.

\section{Method and Materials}

The flow of the blood at the frontal part of the brain was measured using 16-channel optical encephalography (Figure1), using the OEG-APD series instrument (Figure 2) developed for encephalography to measure chemical changes in the brain such as hemoglobin levels and apparent arterial oxygen saturation in the frontal lobe [51]. Optical Encephalography is a functional Near-Infrared Spectroscopy.Near-infrared spectroscopy (NIRS) is a spectroscopic method that uses the nearinfrared region of the electromagnetic spectrum (from $780 \mathrm{~nm}$ to $2500 \mathrm{~nm}$ ) for physiological diagnostics such as serum glucose, pulse oximetry, $\mathrm{pO} 2$, serum $\mathrm{Hb}$ and many others using a diversity of coupling interfaces [52].

Dr. Nobuhiro Maruyamaon supervised and operating the testing equipment. A cerebral blood flow baseline value was established. The WaveRider ${ }^{\circledR}$, noise field generator was engaged. The cerebral blood flow was measured.

\section{Results}

330 seconds after the start of the measurement, the WaveRider ${ }^{\circledR}$ noise field was engaged. The red line indicates the interpretation of the blood flow based on the PO2 and $\mathrm{Hb}$ (increased oxygen and hemoglobin saturation rate). Immediately after the WaveRider ${ }^{\circledR}$ was engaged, the blood flow increased at 15 of the 16 channels (Figure 3 ).

Figure 4 below shows the interpretation of the blood flow based on the increased oxygen hemoglobin saturation rate. $\mathrm{PO} 2$ and $\mathrm{Hb}$ at 7.209 seconds after the start of the Noise field generator was engaged, indicating baseline measurements previous to the WaveRider ${ }^{\circledast}$ initiation effects to the left. Figure 5 shows the interpretation of $\mathrm{PO} 2$ and Hbvalues for the duration of the monitoring up to 864.419 seconds. 
Figure 1 -flow of the blood at the frontal part of the brain was measured using 16-channel optical encephalography using the OEG-APD series instrument developed for encephalography

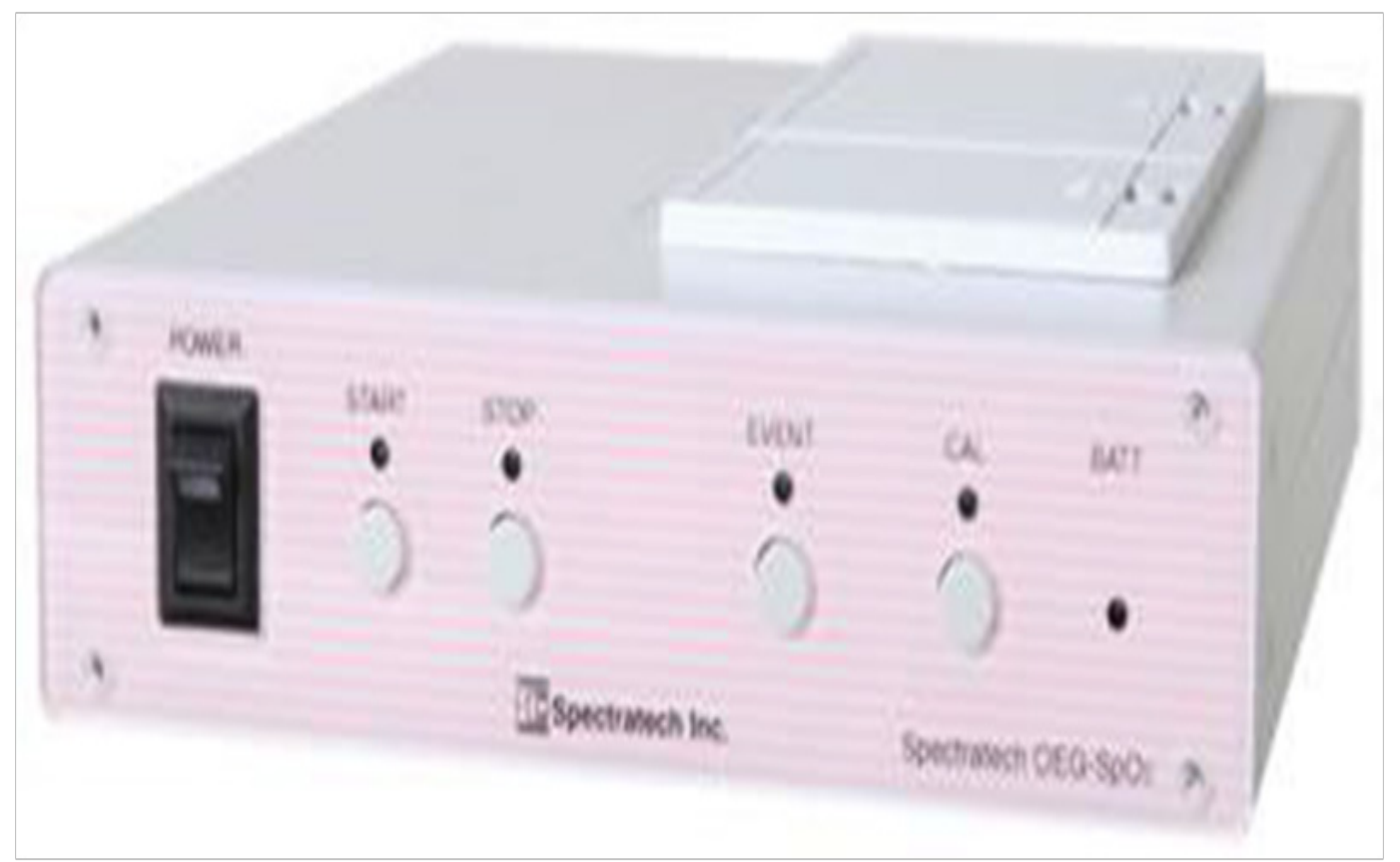

Figure 2: 16-channel optical encephalography using the OEG-APD series instrument developed for encephalography 


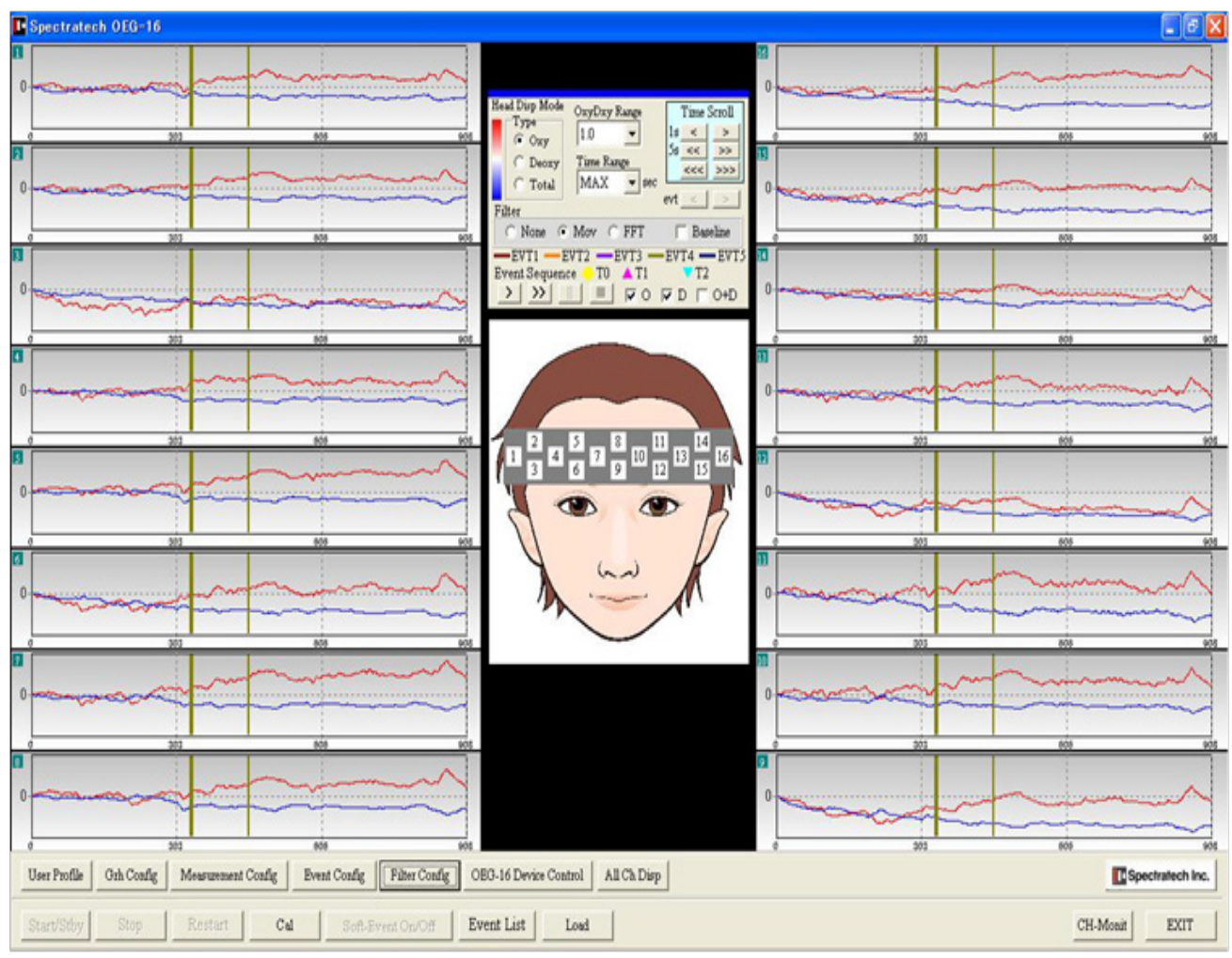

Figure 3 Post WaveRider ${ }^{\oplus}$ initiation, the blood flow increased at 15 of the 16 channels

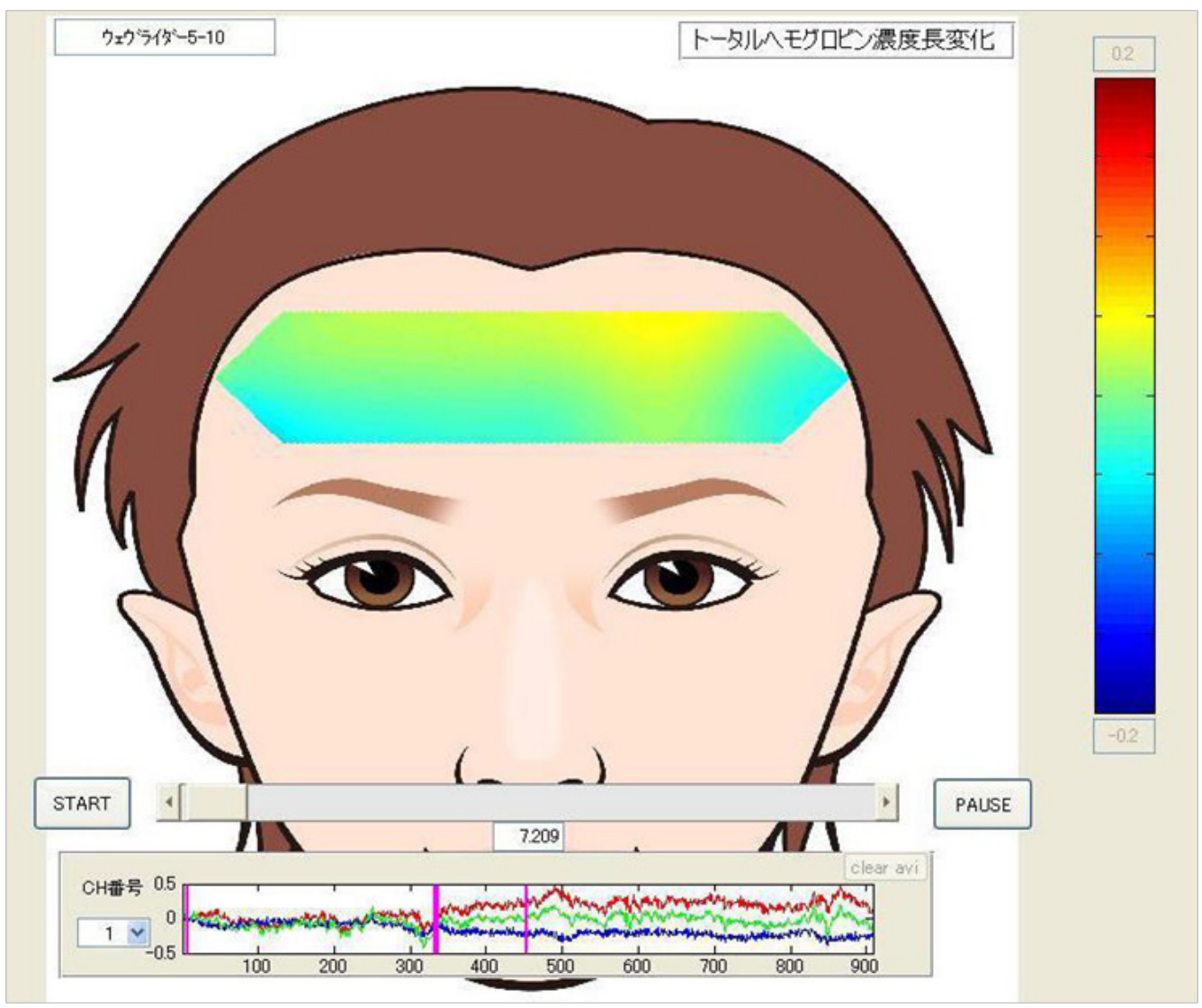

Figure 4 shows the interpretation of the blood flow based on the increased oxygen hemoglobin saturation rate. PO2 and $\mathrm{Hb}$ at 7.209 seconds after the start of the Noise field generator was engaged. 


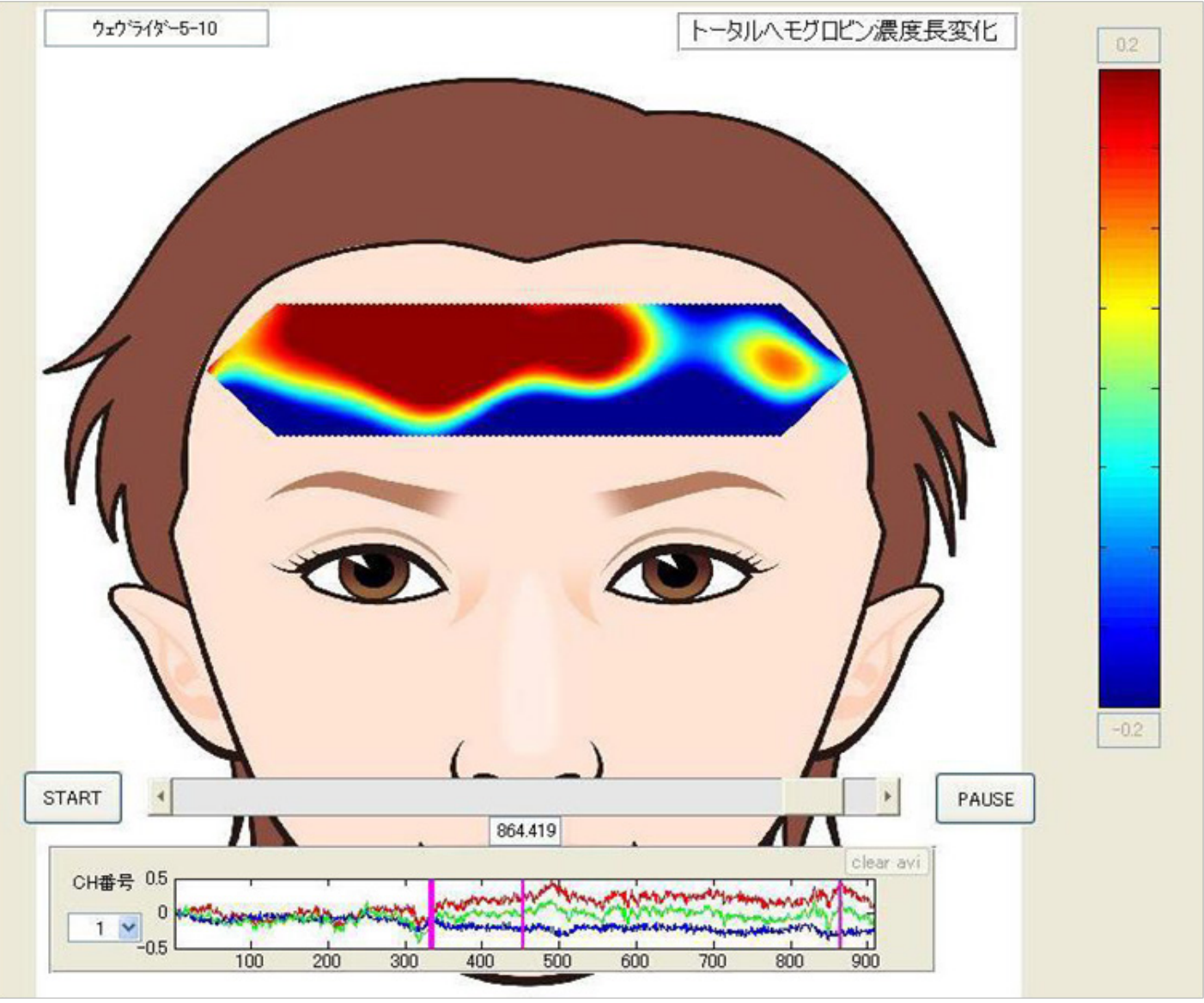

Figure 5 shows the interpretation ofPO2 and Hbvalues for the duration of the monitoring up to 864.419 seconds.

\section{Discussion}

The Optical Encephalograph is a functional NearInfrared Spectroscopy (fNIRS) device that monitors PO2 and hemoglobin $(\mathrm{Hb})$ levels and translates the data into an indication of blood flow. BBB increased permeability decreases cerebral blood flow and conversely one may confer that increased cerebrovascular blood flow indicates a decrease to BBB permeability $[53,54]$. While increasing cerebral PO2 and Hemoglobin are both beneficial, these parameters are not within the discussion parameters of this paper. An increase in the BBB's normally low permeability for hydrophilic and charged molecules could potentially be detrimental [55].” EMR causes increased BBB (add PO2 Hg) permeability [56-63]. Spatially coherent magnetic noise fields have been shown to interfere with the physiological reception of the damaging components of radiation at the cellular level and overall offer a form of shielding and consequently minimal and/or no damage can ensue [6472]. The MRET polymerincorporates passive magnetic noise field technology to interrupt the perception of electromagnetic radiation wave form from the receptors the body. This technology, used in the construction of the Wave Rider device, involves the superimposition of a random noise field wave onto damaging electromagnetic wave forms thereby eliminating all effects [73-75].
The MRET- Nylon Polymer compound has a special fractal geometric structure. The nature of fractal nano-rings structure and enhanced piezoelectric properties of this compound generates random, subtle, low frequency oscillations when exposed to the external electromagnetic or radio frequency radiation. The polymer has been shown to significantly decrease or eliminate the physiological effects of electromagnetic radiation [76]. The Patented MRET-Shield polymer has been laboratory tested involving standard acceptable physiological criteria such as EEG, MRA (magnetic resonance angiography), SAR (specific absorption rate), thermography, live blood cell microscopic analysis, and Complete Blood Count (CBC) and therefore could account for the changes that have occurred in this experiment [77].

Disorders or disruptions of the blood-brain-barrier, resulting in changes to its permeability, can lead to pathogens and toxic substances penetrating into the brain more easily. This may consequently cause cerebral edema which depending on the size can increase cerebral pressure resulting in circulatory disorders [78]. Alzheimer's disease (AD) is a chronic neurodegenerative disorder categorized by the accumulation of amyloid beta $(A \beta)$ peptides, neurofibriltangles with hyperphosphorylated neuronal tau protein, and chronic brain inflammation. 
The blood-brain barrier (BBB), a highly specialized protective cell membrane located along the walls of cerebral blood vessels, characterizes the interface between the neurological tissue of the brain and circulating cells of the immune system. The $\mathrm{BBB}$ therefore is responsible for the maintenance and protection against chronic inflammation during $\mathrm{AD}$ [79]. It may be concluded that since EMR disrupts the integrity and permeability of the BBB [80-85], and the MRET polymer technology inhibits or eliminates physiological effects of EMR, that there may be a positive correlation on the effects of the MRET polymer noise field generator (WaveRider ${ }^{\circ}$ ), and the onset and progression of Alzheimer's Disease.The question of whether the opening of the blood-brain barrier constitutes a health hazard demands further investigation [86], especially with the increasing incidence of Alzheimer's Disease which is characterized by the pathological accumulation of amyloid beta $(A \beta)$ peptides, neurofibrillary tangles containing hyperphosphorylated neuronal tau protein, and chronic brain inflammation [87].

Further, understanding that the brain has a very high metabolic demand for oxygen compared to other organs, any increase in the cerebral circulation that produces marked increases in cerebral blood flow is beneficial [88]. Since the brain uses $\sim 20 \%$ of available oxygen for normal function, making tight regulation of blood flow and oxygen delivery critical for survival, improving cerebral blood flow has potential benefits [89].

\section{Conclusion}

The noise field generated by the WaveRider ${ }^{\circledR}$ increases the blood flow at the frontal part of the brain remarkably within the optimal range of normal limits. The results of the current study indicates that the WaveRider ${ }^{\bullet}$ device has the ability to affect the human brain in a way that leads to an increase of the blood brain circulation and may compensate any unwanted biological effect of radio frequency EMF related to BBB leakage. This result correlates with previous in vitro studies of the WaveRider ${ }^{\circ}$ noise field effect on the metabolic activity of human astrocyte cells exposed to microwave radiation which confirmed that WaveRider ${ }^{\circ}$ device placed at the distance of 30 feet from the treated plates had a measurable compensatory effect on the inhibition of normal human brain Astrocyte cells growth when cells were exposed to mobile phone irradiation [90].

5.2 Further investigation is necessary since maintaining the integrity or decreasing the permeability of the $\mathrm{BBB}$ may delay the onset and or progression of $\mathrm{AD}$ and other diseases related to inflammation or cerebral toxicity. Increased cerebral blood flow can also increase oxygen content allowing less degeneration, atrophy or issues from potential anoxic situations.

\section{References}

1) Wertheimer N, Leeper E (1982) Adult cancer related to electrical wires near the home. Int J Epidemiol 11:345-355.

2) Poole C, Trichopoulis D (1991) Extremely low-frequency magnetic fields and cancer. Cancer Causes Control 2: 267-276.

3) Adey W R (1987) Evidence for tissue interactions with microwave and other nonionizing electromagnetic fields in cancer promotion. In Fiala J and Pokorny J (eds). Biophysical Aspects of Cancer. Charles University. Prague.

4) Draper G, Vincent T, Kroll M E, Swanson J (2005) Childhood cancer in relation to distance from high voltage power lines in England and Wales: a case controlled study. BMJ 330: 1290-1295.

5) Baris D, Armstrong B G, Deadman J, Theriault G (1996) A mortality study of electrical utility workers in Quebec. Occupational and Environmental Medicine 53: 25-31.

6) Desai NR, Kesari KK, Agarwal A (2009) Pathophysiology of cell phone radiation: oxidative stress and carcinogenesis with focus on male reproductive system. Reprod Biol Endocrinol 7:114.

7) Sepehrimanesh M, Davis DL. Proteomic impacts of electromagnetic fields on the male reproductive system. Comp Clin Path [Internet]. Springer London 26: 309-313.

8) Sajeda S, Al-Watter Y (2011) Effect of mobile phone usage on semen analysis in infertile men. Tikrit J Pharm Sci 7: 77-82.

9) Agarwal A, Deepinder F, Sharma RK, Ranga G, Li J (2008) Effect of cell phone usage on semen analysis in men attending infertility clinic: an observational study. Fertil Steril 89: 124-28.

10) Sadetzki S, Chetrit A, Jarus-Hakak A, Cardis E, Deutch Y, et al. ( 2008) Cellular Phone Use and Risk of Benign and Malignant Parotid Gland Tumors-A Nationwide Case-Control Study. Am J Epidemiol 167: 457-467.

11) Erogul O, Oztas E, Yildirim I, Kir T, Aydur E, et al. (2006) Effects of electromagnetic radiation from a cellular phone on human sperm motility: An in vitro study. Arch Med Res 37: 840-843.

12) Agarwal A, Desai NR, Makker K, Varghese A, Mouradi R, et al. (2009) Effects of radiofrequency electromagnetic waves (RF-EMW) from cellular phones on human ejaculated semen: an in vitro pilot study. Fertil Steril 92: 1318-1325.

13) Ahmed L, Baig NM (2011) Mobile phone RF-EMW exposure to human spermatozoa: an in vitro study. Pak J Zool 43: 1147-1154.

14) De Iuliis G, Newey R, King B, Aitken R (2009) Mobile phone radiation induces reactive oxygen species production and DNA damage in human spermatozoa in vitro. PLoS One 4:e6446.

15) Gandhi G, Singh P (2005) Mobile phone users: Another high health risk group. J Hum Ecol 18: 85-92.

16) Salford L, Brun A E, Eberhardt J L, Malmgren L, Persson B R (2003) "Nerve Cell Damage in Mammalian Brain After Exposure to Microwaves from GSM Phones." Environmental Health Perspectives. 111: 881-883.

17) Lahkola A, Auvinen A, Raitanen J, Schoemaker M J, Christensen H C, et al. (2007) Mobile phone use and the risk of glioma in 5 North European Countries. Int J Cancer 120: 1769-1775.

18) Khurana V (2008) International Journal of Oncology 22: 399-407.

19) Lahkola A, Auvinen A, Raitanen J, Schoemaker M J, Christensen $\mathrm{H}$ C, et al. ( 2007) Mobile phone use and the risk of glioma in 5 North European Countries. Int J Cancer 120: 1769-1775.

20) Morgan L L (2008) Interphone Brain Tumors Studies To Date: An Examination of Poor Study Design Resulting in an UNDER-ESTIMATION of the Risk of Brain Tumors. BEMS, San Diego.

21) Morgan L L (2008) Interphone Brain Tumors Studies To Date: An Examination of Poor Study Design Resulting in an UNDER-ESTIMATION of the Risk of Brain Tumors. BEMS, San Diego. 
22) N.J. Abbott, A.A. Patabendige, D.E. Dolman, S.R. Yusof, D.J (2010) Begley Structure and function of the blood-brain barrier Neurobiol. Dis 37: 13-25.

23) Zenaro E, Piacentino G, Constantin G (2017) The blood-brain barrier in Alzheimer's disease. Neurobiol Dis 107: 41-56.

24) Stam R (2010) Electromagnetic fields and the blood-brain barrier, Brain Res Rev 65: 80-97.

25) Aalto $S$, Haarala $C$, Brück $A$, Sipilä $H$, Hämäläinen $H$, et al. (2006) Mobile phone affects cerebral blood flow in humans. Journal of Cerebral Blood Flow \& Metabolism 26: 885-890.

26) Stam R. (2010) Electromagnetic fields and the blood-brain barrier. Brain Res Rev 65: 80-97.

27) Salford L G, Brun A, Sturesson K, Eberhardt J L, Persson B R (1994) Permeability of the blood-brain barrier induced by $915 \mathrm{MHz}$ electromagnetic radiation, continuous wave and modulated at 8,16 , 50, and $200 \mathrm{~Hz}$. Microsc Res Tech 27: 535-542.

28) Salford L, Brun A E, Eberhardt J L, Malmgren L, Persson B R (2003) "Nerve Cell Damage in Mammalian Brain After Exposure to Microwaves from GSM Phones." Environmental Health Perspectives 111: 881-883.

29) Schirmacher A, Winters S, Fischer S, Goeke J, Galla HJ, et al. (2000) Electromagnetic fields $(1.8 \mathrm{GHz})$ increase the permeability to sucrose of the blood-brain barrier in vitro. Bioelectromagnetics 21: 338-345.

30) Poulletier de Gannes F, Masuda H, Billaudel B, Poque-Haro E, Hurtier A, et al. (2017) Effects of GSM and UMTS mobile telephony signals on neuron degeneration and blood-brain barrier permeation in the rat brain. .Sci Rep 7: 15496.

31) Nittby H, Grafström G, Eberhardt JL, Malmgren L, Brun A, et al. (2008) Salford LG.Radiofrequency and extremely low-frequency electromagnetic field effects on the blood-brain barrier. Electromagn Biol Med. 27: 103-126.

32) Nittby H, Brun A, Eberhardt J, Malmgren L, Persson BR, et al. (2009) Increased blood-brain barrier permeability in mammalian brain 7 days after exposure to the radiation from a GSM-900 mobile phone. Pathophysiology. 16: 103-112.

33) Sirav B, Seyhan N (2009) Blood-Brain Barrier Disruption by Continuous Wave Radio Frequency Radiation, Electromagnetic Biology and Medicine 27.

34) Sirav B, Seyhan N (2016) Effects of GSM modulated radio-frequency electromagnetic radiation on permeability of blood-brain barrier in male and female rats. J Chem Neuroanat 75: 123.

35) Nawashiro H, Shima K, Chigasaki H (1994) Blood-brain barrier, cerebral blood flow, and cerebral plasma volume immediately after head injury in the rat. Acta Neurochir Suppl (Wien) 60: 440-442.

36) Jingtao J, Sato S• Yamanaka N (1999) Changes in cerebral blood flow and blood brain barrier in the gerbil hippocampal CA1 region following repeated brief cerebral ischemia. Med Electron Microsc 32: 175-183.

37) Litovitz T A, Krause D, Montrose C J, Mullins J M (1994) Temporally incoherent magnetic fields mitigate the response of biological systems to temporally coherent magnetic fields. Bioelectromagnetics 15: 399-409.

38) Litovitz T A, Penafiel L M, Farrel J M, Krause D, Meister R, et al. (1997) Bioeffects induced by exposure to microwaves are mitigated by superposition of ELF noise. Bioelectromagnetics 18: 422-430.

39) Litovitz T A, Montrose C J, Doinov P, Brown K M, Barber M (1994) Superimposing spatially coherent electromagnetic noise inhibits field-induced abnormalities in developing chick embryos. Bioeletromagnetics 15: 105-113.

40) Litovitz T.A, Penafiel L.M, Farrel J.M, Krause D, et al. (1997) Bioeffects induced by exposure to microwaves are mitigated by superposition of ELF noise. Bioelectromagnetics 18: 422-430.
41) Wu W, Yao K, Wang K J, Lu D Q, He J L, et al. (2008) Blocking $1800 \mathrm{MHz}$ mobile phone radiation-induced reactive oxygen species production and DNA damage in lens epithelial cells by noise magnetic fields. Zhejiang Da Xue Xue Bao Yi Xue Ban 37: 34-38.

42) Yao K, et al. (2008) "Electromagnetic noise inhibits radiofrequency radiation-induced DNA damage and reactive oxygen species increase in human lens epithelial cells". Molecular Vision 14: 964-969.

43) (2006) Smirnov I V. Polymer Material Providing Compatibility between Technologically Originated EMR and Biological Systems. Explore Magazine 4: 26-32.

44) (2002) Smirnov I V. Electromagnetic Radiation Optimum Neutralizer. Explore Magazine 11: 45-50.

45) Fisher H W, Pisarek S, Smirnov I V (2008) The Beneficial Effect of MRET-Shield on Blood Morphology in Vitro Following the Exposure to Electromagnetic Radiation of Cell Phone. Explore Magazine.

46) Fisher H W, Gauvin C, Pisarek S (2010) Darkfield Microscopic Evaluation of the Noise Field Polymer on the Reduction of Live Blood Effects Caused by Radio Frequency Radiation. Explore magazine 19: 3.

47) Fisher H W. Pisarek S, Smirnov I V (2009) Thermographic Evaluation of the MRET-Shield Polymer on the Reduction of Thermal Effects Caused by Radio Frequency Radiation. Explore Magazine 18: 14-17.

48) Fisher H W, Gauvin C, Pisarek S (2009) The Effect of Radio Frequency Radiation (RFR) from Cell Phone Usage on In Vitro Human Astrocyte Cells (Glial Cells) and the Subsequent Intervention of the MRET Polymer on RFR Effects. Explore Magazine 18-24.

49) Smirnov I V (2009) Synopsis: Exposure of Normal Human Astrocytes Cells to Mobile Phone Radiation with and without MRETNylon Protection. Global Quantech, Inc.

50) Smirnov I.V. (2011) The Passive Generation of Low Frequency Noise Field by MRET-Shield Polymer Compound and Following Amplitude Modulation of RF Carrier Signals. International Journal of Biophysics 1: 1-10.

51) http://www.spectratech.co.jp/En/product/productOegSpo2En. html

52) Treado P. J, Levin I. W, Lewis E. N (1992) "Near-Infrared AcoustoOptic Filtered Spectroscopic Microscopy: A Solid-State Approach to Chemical Imaging". Applied Spectroscopy 46: 553-559.

53) Nawashiro H, Shima K, Chigasaki H (1994) Blood-brain barrier, cerebral blood flow, and cerebral plasma volume immediately after head injury in the rat. Acta Neurochir Suppl (Wien) 60: 440-442. 54) Jingtao J, Sato S, Yamanaka N (1999) Changes in cerebral blood flow and blood brain barrier in the gerbil hippocampal CA1 region following repeated brief cerebral ischemia. Med Electron Microsc 32: 175-183.

55) Stam R. (2010) Electromagnetic fields and the blood-brain barrier. Brain Res Rev 65: 80-97.

56) Salford L G, Brun A, Sturesson K, Eberhardt J L, Persson B R, et al. (1994) Permeability of the blood-brain barrier induced by $915 \mathrm{MHz}$ electromagnetic radiation, continuous wave and modulated at 8,16 , 50, and $200 \mathrm{~Hz}$. Microsc Res Tech. 27: 535-542.

57) Salford L, Brun A E, Eberhardt J L, Malmgren L, Persson B R (2003) "Nerve Cell Damage in Mammalian Brain After Exposure to Microwaves from GSM Phones." Environmental Health Perspectives. 111: 881-883.

58) Schirmacher A, Winters S, Fischer S, Goeke J, Galla HJ, Kullnick $\mathrm{U}$ (2000) Electromagnetic fields $(1.8 \mathrm{GHz})$ increase the permeability to sucrose of the blood-brain barrier in vitro. Bioelectromagnetics. 21: 338-345.

59) Poulletier de Gannes F, Masuda H, Billaudel B, Poque-Haro E, Hurtier A, et al. (2017) Effects of GSM and UMTS mobile telephony signals on neuron degeneration and blood-brain barrier permeation in the rat brain. Sci Rep 7: 15496. 
60) Nittby H, Grafström G, Eberhardt JL, Malmgren L, Brun A, et al. (2008) Salford LG.Radiofrequency and extremely low-frequency electromagnetic field effects on the blood-brain barrier. Electromagn Biol Med 27: 103-126.

61) Nittby H, Brun A, Eberhardt J, Malmgren L, Persson BR, et al. (2009) Increased blood-brain barrier permeability in mammalian brain 7 days after exposure to the radiation from a GSM-900 mobile phone. Pathophysiology 16: 103-112.

62) Sirav B, Seyhan N (2009) Blood-Brain Barrier Disruption by Continuous Wave Radio Frequency Radiation, Electromagnetic Biology and Medicine 27.

63) Sirav B, Seyhan N (2016) Effects of GSM modulated radio-frequency electromagnetic radiation on permeability of blood-brain barrier in male and female rats. J Chem Neuroanat 75: 123.

64) Li C, Jiang H, Fu Y (1998) A study on dose-effect of suppression to gap junctional intercellular communication function by $50-\mathrm{Hz}$ magnetic fields]Zhonghua Yu Fang Yi Xue Za Zhi 32: 142-144.

65) Zeng Q, Chiang H, Fu Y, Lu D, Xu Z Electromagnetic noise blocks the gap-junctional intercellular communication suppression induced by $50 \mathrm{~Hz}$ magnetic field]

66) Zhonghua Lao Dong Wei Sheng Zhi Ye Bing Za Zhi (2002) 20: 243-245.

67) Litovitz T A, Montrose C J, Doinov P, Brown K M, Barber M (1994) Superimposing spatially coherent electromagnetic noise inhibits field-induced abnormalities in developing chick embryos. Bioeletromagnetics 15: 105-113.

68) Litovitz T A, Penafiel L M, Farrel J M, Krause D, Meister R, et al. (1997) Bioeffects induced by exposure to microwaves are mitigated by superposition of ELF noise. Bioelectromagnetics 18: 422-430.

69) Litovitz T A, Krause D, Montrose C J, Mullins J M (1994) Temporally incoherent magnetic fields mitigate the response of biological systems to temporally coherent magnetic fields. Bioelectromagnetics 15: 399-409.

70) Yao K, Wu W, Wang K, Ni S, Ye P, et al. (2008) Electromagnetic noise inhibits radiofrequency radiation-induced DNA damage and reactive oxygen species increase in human lens epithelial cells. Mol Vis 14: 964-969.

71) Yao K, Wu W, Yu Y, Zeng Q, He J, et al. (2008) Effect of superposed electromagnetic noise on DNA damage of lens epithelial cells induced by microwave radiation. Invest Ophthalmol Vis Sci 49: 2009-2015.

72) Wu W, Yao K, Wang K J, Lu D Q, He J L, et al. (2008) Blocking $1800 \mathrm{MHz}$ mobile phone radiation-induced reactive oxygen species production and DNA damage in lens epithelial cells by noise magnetic fields. Zhejiang Da Xue Xue Bao Yi Xue Ban 37: 34-38.

73) Li C, Jiang H, Fu Y (1998) A study on dose-effect of suppression to gap junctional intercellular communication function by $50-\mathrm{Hz}$ magnetic fields] Zhonghua Yu Fang Yi Xue Za Zhi 32: 142-144.

74) Zeng Q, Chiang H, Fu Y, Lu D, Xu Z (2002) Electromagnetic noise blocks the gap-junctional intercellular communication suppression induced by $50 \mathrm{~Hz}$ magnetic field] Zhonghua Lao Dong Wei Sheng Zhi Ye Bing Za Zhi 20: 243-245.

75) Litovitz T A, Montrose C J, Doinov P, Brown K M, Barber M (1994) Superimposing spatially coherent electromagnetic noise inhibits field-induced abnormalities in developing chick embryos. Bioeletromagnetics 15: 105-113.

76) Smirnov IV (2006) Polymer Material Providing Compatibility between Technologically Originated EMR and Biological Systems. Explore Magazine 4: 26-32.

77) Fisher H W, Pisarek S, Smirnov IV (2008) The Beneficial Effect of MRET-Shield on Blood Morphology in vitro Following the Exposure to Electromagnetic Radiation of Cell Phone. Explore Magazine 17.
78) Stam R (2010) Electromagnetic fields and the blood-brain barrier, Brain Res Rev 65: 80-97.

79) Zenaro E, Piacentino G, Constantin G (2017) The blood-brain barrier in Alzheimer's disease. Neurobiol Dis 107: 41-56.

80) Salford L G, Brun A, Sturesson K, Eberhardt J L, Persson B R (1994) Permeability of the blood-brain barrier induced by $915 \mathrm{MHz}$ electromagnetic radiation, continuous wave and modulated at 8, 16, 50, and $200 \mathrm{~Hz}$. Microsc Res Tech 27: 535-542.

81) Salford L, Brun A E, Eberhardt J L, Malmgren L, Persson B R (2003) "Nerve Cell Damage in Mammalian Brain After Exposure to Microwaves from GSM Phones." Environmental Health Perspectives 111: 881-883.

82) Schirmacher A, Winters S, Fischer S, Goeke J, Galla HJ (2000) Electromagnetic fields $(1.8 \mathrm{GHz})$ increase the permeability to sucrose of the blood-brain barrier in vitro. Bioelectromagnetics 21:338-345. 83) Poulletier de Gannes F, Masuda H, Billaudel B, Poque-Haro E, et al. (2017) Effects of GSM and UMTS mobile telephony signals on neuron degeneration and blood-brain barrier permeation in the rat brain. .Sci Rep 7: 15496.

84) Nittby H, Grafström G, Eberhardt JL, Malmgren L, Brun A, et al (2008) Radiofrequency and extremely low-frequency electromagnetic field effects on the blood-brain barrier. Electromagn Biol Med 27: 103-126.

85) Nittby H, Brun A, Eberhardt J, Malmgren L, Persson BR,et al. (2009) Increased blood-brain barrier permeability in mammalian brain 7 days after exposure to the radiation from a GSM-900 mobile phone.Pathophysiology 16: 103-112.

86) Salford L G, Brun A, Sturesson K, Eberhardt J L, Persson B R (1994) Permeability of the blood-brain barrier induced by $915 \mathrm{MHz}$ electromagnetic radiation, continuous wave and modulated at 8,16 , 50, and $200 \mathrm{~Hz}$. Microsc Res Tech 27: 535-542.

87) Zenaro E, Piacentino G, Constantin G (2017) The blood-brain barrier in Alzheimer's disease. Neurobiol Dis 107: 41-56.

88) Masamoto K, Tanishita K (2009) Oxygen transport in brain tissue. J Biomech Eng 131: 74-82.

89) Clarke DD, Sokoloff L (1989) Circulation and energy metabolism of the brain. In: Basic Neurochemistry, Siegel G, Agrano BV, Albers RW, Molino PV (Eds.) New York: Raven Press 565-590.

90) Smirnov IV (2013) The Effect of MRET Noise Field Generator on Metabolic Activity of Astrocyte Cells Exposed to RF Phones Radiation, European Journal of Science and Engineering.

Submit your manuscript to a JScholar journal and benefit from:

ฯ Convenient online submission

ฯ Rigorous peer review

ฯ Immediate publication on acceptance

ब Open access: articles freely available online

q High visibility within the field

ब Better discount for your subsequent articles Submit your manuscript at http://www.jscholaronline.org/submit-manuscript.php 